\title{
INFLUENCE OF CLEANLINESS, ANNEALING TEMPERATURE AND NOTCH ROOT RADIUS ON TOUGHNESS PROPERTIES OF AISI 316 STAINLESS STEEL
}

\section{G. Hebsur and J. J. Moore}

Mineral Resources Research Center, University of Minnesota, 56 East River Road, Minneapolis.

\section{ABSTRACT}

It has been reported for low alloy structural steels that high temperature austenitizing treatments at $1473 \mathrm{~K}$ instead of conventional heat treatment at $1143 \mathrm{~K}$ result in a twofold increase in $\mathrm{K}_{\mathrm{Ic}}$, but a decrease in CVN energy. This paper seeks to establish whether such a discrepancy in charpy and $K_{I c}$ data exists for steels other than low alloy structural steels such as AISI 316 stainless steel. The influence of cleanliness, annealing temperature and notch root radius on the toughness properties of AlSI 316 stainless steel has been investigated. It is found that both $K{ }_{1 c}$ and CVN energy values increased

with an increase in the levels of cleanliness, annealing temperature and notch root radius.

\section{KEYWORDS}

Notch root radius; cleanliness; annealing temperature; CVN fracture energy; dynamic fracture toughness; impurity segregation; characteristic distance; critical fracture stress.

\section{INTRODUCTION}

Studies on the influence of high temperature austenitizing treatments on the mechanical properties of commercial ultra high strength, low alloy steels in either the untempered or tempered condition, have shown an anomaly in their effect upon the toughness characteristics of these steels. The plane strain fracture toughness $\mathrm{K}_{\mathrm{Ic}}$ increases (Zackay and co-workers, 1972; Ritchie and

Horn, 1978) whereas the CVN fractures' energy decreases with increase in austenitizing temperatures (Lai and co-workers, 1974; McDarmaid, 1978). The dynamic fracture toughness $K_{1 d}$ of as-quenched AISI 4340 steel, however, has been found to increase with increase in austenitizing temperature (Ritchie, Francis and Server, 1976). 
1402

This paradoxical behaviour has been rationalized in terms of the differing response fo the ( $k_{1 c}$ or $k_{1 d}$ ) has been attributed mainly to improved characteristic distance due to either grain coarsening or increased particle distance occurring at higher temperatures. On the other hand, the decrease in blunt toughness at higher austenitizing temperatures has been attributed to reduction in critical fracture stress or strain due to either grain boundary embrittlement or increased strain concentration at the martensite lath boundaries (Ritchie and Horn, 1978; Ritchie, Franci.s and Server, 1976). These observations highlight the total lack of direct correlation between $K_{1 c}$ and $C V N$ values in ultra high strength steels. The existing empirical correlations cannot predict an inverse trend of increasing $K$ with decreasing CVN energy as observed in ultra high strength steels. Therefare, it appears insufficient to grade material toughness solely on the basis of $K_{1 c}$ or CVH.

In the present investigation the aim was, first of all, to examine whether there is an inverse trend of increasing $K_{I c}$ with decreasing CVN energy as a function of austenitizing temperature for steels other than low alloy structural steels; secondly, to assess the influence of cleanliness, grain size and notch root radius on the fracture behaviour. Alsl austenitic stainless stee

\section{EXPERIMENTAL}

AlSI 316 austenitic stainless steel, melted in an electric arc furnace and an Alsi 316 austentecinafer designated as unrefectric university of British Columbia, had the following chemical composition:

\begin{tabular}{lcccccccc}
\multicolumn{10}{c}{ TABLE 1 } \\
\hline Unrefined & C & $P$ & Mn & S & Si & Cr & Ni & Mo \\
Refined & 0.072 & 0.038 & 1.58 & 0.011 & 0.89 & 16.8 & 12.0 & 2.13 \\
& 0.077 & 0.035 & 1.54 & 0.0065 & 0.78 & 17.0 & 12.5 & 2.15 \\
\hline
\end{tabular}

As-received steel in cast condition was forged down to $15.24 \times 30.48 \mathrm{~mm}$ section bars. $0.762 \mathrm{~mm}$ ) and compact tension specimens of $12.7 \mathrm{~mm}$ thickness of ASTM specifications were machined from the forged stock. All the specimens were solutio treated for two hours in the temperature range of $1173 \mathrm{~K}$ to $1473 \mathrm{~K}$ followed by water quench.

Charpy specimens were broken on a dynatup instrumented impact-testing machine. To evaluate the dynamic fracture toughness $\left(k_{1 d}\right)$, some of the charpy specimens were fatigue precracked on a precracker and then were broken on an instrumented impact testing machine. The complete experimental procedure for dynamic $\mathrm{K}_{\mathrm{Id}}$ testing has been described elsewhere (Server, Ireland and Wullaert, 1974)。

Fracture toughness testing was carried out according to the ASTM 399 procedure (Annual Book of ASTM Standards, 1978) on a 10-ton MTS machine. All mechanical property testing actured samples were property testing was carried out at room tome (SEM) which was interfaced wi examined using a scanning electron (EDX) facility. Detailed quantitative an energy dispersive $x$-ray and grain size measurements was carried out on standard specimens under heat treated conditions.

\section{RESULTS}

The chemical analysis given in Table I shows that the sulphur content of the The composition of other alloying elements remained well within the specified limits. The distribution of inclusions before and after ESR is shown in Fig. in the dorm oxides, silicates, and sulphides. Fig. I demonstrates that larger inclusions ore completely eliminated in ESR steel, thereby remarkably improving cleanliness. The mean inclusions spacing for specimens heat treated at various an-

nealing temperatures is shown in Fig. 2 where it is seen that the

treated at various solution an which indicates that austenite figer series grain size increases with the annealing condition of specimens treated with various annealing temperatures.

Typical load (energy)/time curves obtained on an instrumented impact test for Typical load (energy)/ent at $1473 \mathrm{~K}$ and notch root radius of 0.76 efinely. It is evident that both min) a re shion as total energy to fracture, have increased in the refined steel.

The charpy $V$-notch (CVN) fracture energy values estimated as a function of The charpy -notch for refined and unrefined steel treated at various annealnotch root radics are shown in Fig. 5. Dynamic fracture toughness, $\mathrm{K}_{\mathrm{d}}^{*}$ values ing tome of instrumented impact test data have computed from equivalent energy load of instrumented radius. From Fig. 5 and been plotted in Fir that both CVN fracture energy and apparent fracture Fig. 6 it is clear that and level of cleanliness.

The fracture tougness measured on AISI 316 stainless steel is represented $K$ (critical stress intensity factor) instead of $K_{1 c^{\circ}}$. This is because the $\mathrm{K}_{\mathrm{Q}}$ (critical stres

$B \geq 2.5\left(\frac{K_{l c}}{\sigma_{y}}\right)^{2}$ where $\sigma_{y}$ is the yield stress.

The fracture toughness values obtained on unrefined and refined steel are The fracture toughness values obtained on unrefined and refig. 7 exhibits the following features:

with unrefined steel, the refined steel has highe

fracture toughness values.

(2) toughness values. 
1404

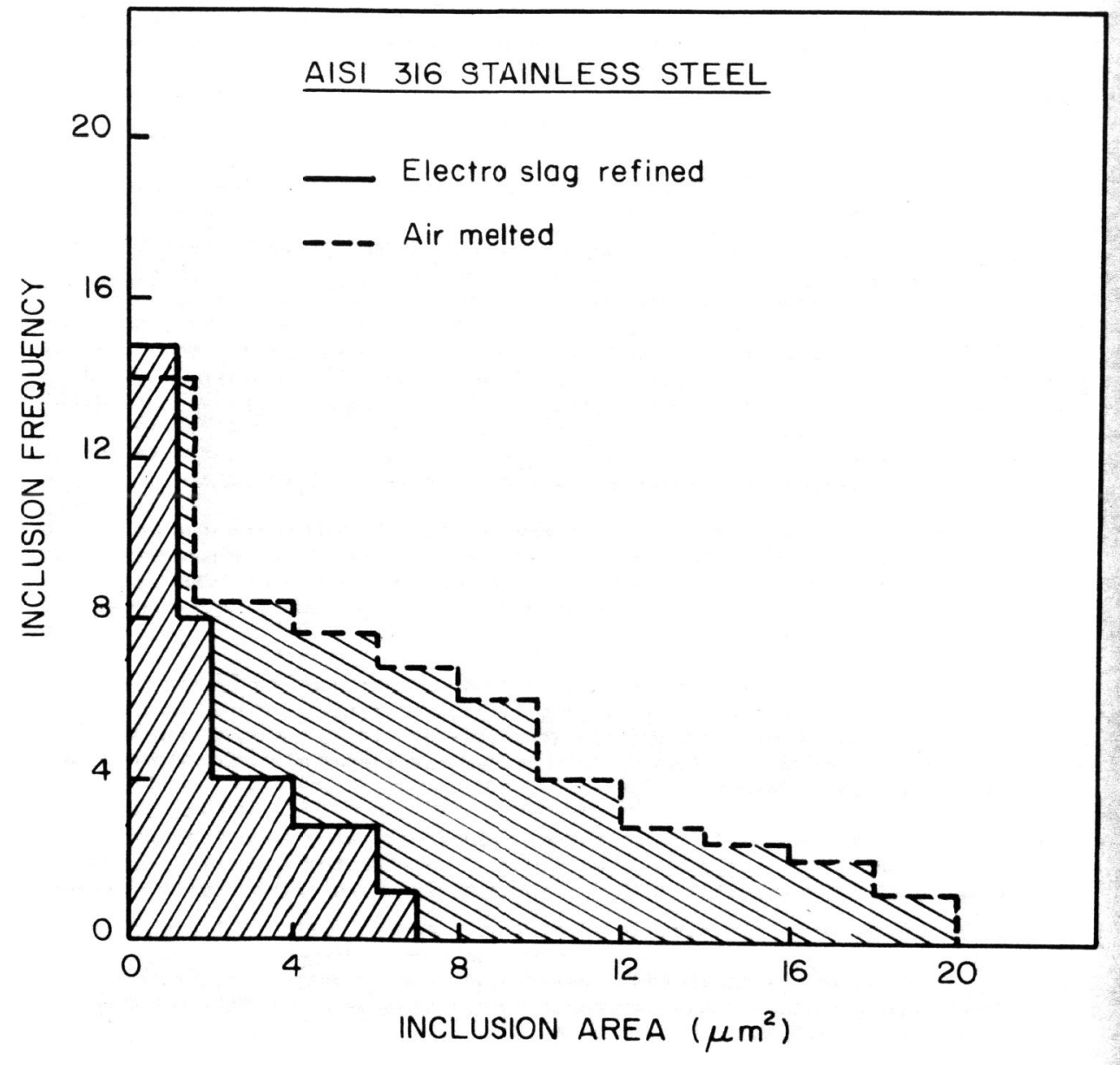

Fig. I. Inclusion distribution in AlSI 316 stainless steel.

DISCUSSION

The chemical composition given in Table 1 and the inclusion distribution documented in Fig. I bear ample evidence that ESR steel is cleaner when compared with the unrefined steel. The mechanical properties (particularly fracture toughness) are sensitive to the presence of inclusions as will the sulphur content in the steel. The role of inclusions in the well as crack propagation has been discussed by Rogers (1967) and Schwalbe (1977) in terms of the well known dimple formation mechanism. The ductile fracture depends on the volume fraction, size and type as well as on the distribution of the inclusions. The most deleterious inclusions are the sulphides and Birkle, Klei and Pellissier (1966) have shown that the $K$.c decreases by

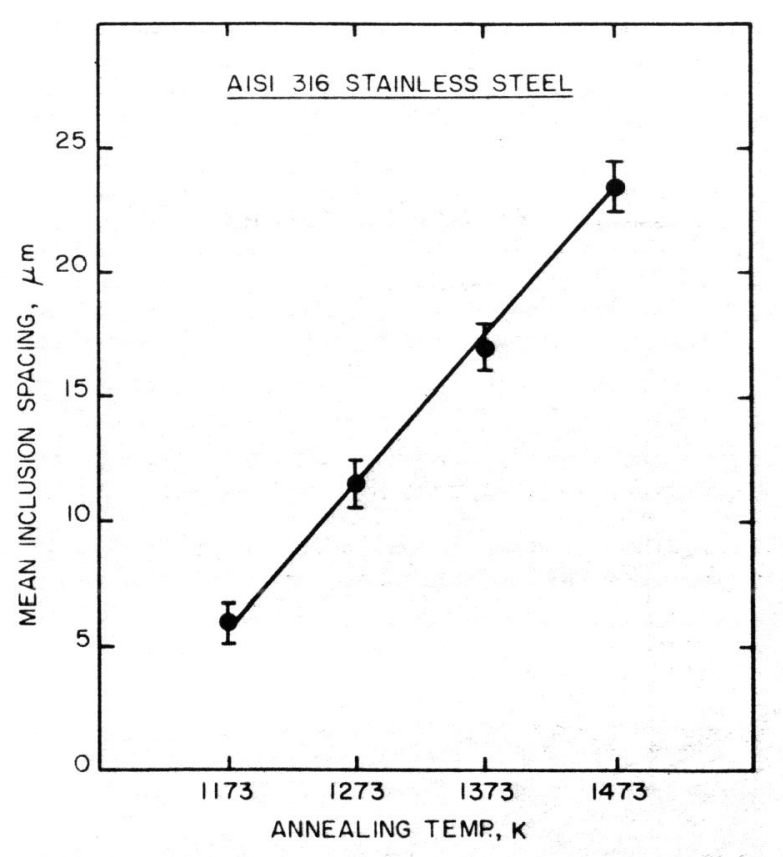

Fig. 2. Variation of mean inclusion spacing with annealing temperature for direct water quenched AlSI 316 stainless steel.

bout $40 \%$ when the sulphur content in the steel is increased from $0.008 \%$ to $0.049 \%$. The fracture toughness is very sensitive to the size of inclusions since the plastic strains necessary to fracture an inclusion increase with decreasing inclusion size. Whereas the particle size determines the onse rowth and crack propagation.

The electroslag refining has eliminated inclusions with areas larger than $3 \mathrm{\mu m}^{2}$; thus the inclusions at which the void formation readily occurs have been removed in ESR steel. Furthermore, the lowering of sulphur content to very small values largely eliminates the detrimental effect of sulphide inclusions. Thus, the improved CVN fracture energy and fracture toughness can be attributed to inclusions removal and reduced sulphur content. The scanning electron micrographs obtained on the CT specimens of unrefined and refined steel are shown in Figs. $3 a$ and $8 \mathrm{~b}$. In the refined steel the dimples caused by finer inclusions ( $F i g$. $3 a$ ) are seen in contrast to those due to large and complex sulphide inclusion in the unrefined steel ( $\mathrm{Fig} .3 \mathrm{~b}$ )

Figs. 5, 6 and 7 indicate that both the CVN energy and fracture toughness of AISI 316 stainless steel is in contrast to that of AlSI 4340 steel. The observed increase in toughness (both CVN and $K_{I c}$ ) of AlSI 316 stainless 


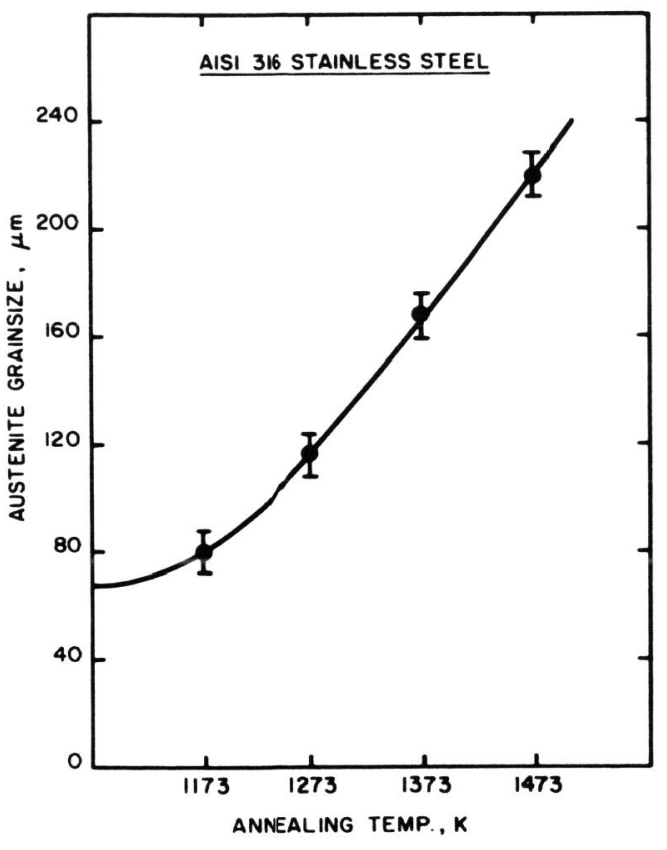

Fig. 3a. Variation in austenite grain size with annealing temperature for direct water quenched AlSI 316 stainless steel.

steel with increase in annealing temperature can be attributed to increased critical fracture stress $\sigma_{F}$ and increased characteristic distance. Chemical homogeneity by a re-solution of residual elements; a reduction in elemental segregation effects; suppression of impurity segregation ( $\mathrm{Clark}$ and Ferguson, 1974; Clark, Ritchie and Knott, 1972) and changes in carbide morphology (Clark, Ritchie and knott, 1972), all of these factors contribute to increase the value of (fracture stress), whereas an increase in characteristic distance is de mainly to grain coarsening as well as to improved particle distance is duering records of fractured charpy specimens of unrefined steel (Figs. $9 a$ and $9 \mathrm{~b}$ ) indicate that failure has occurred by cleavage at both low and high annealing temperatures. Cleavage is largely considered to be stress controlled (Ritchie, Francis and Server). In charpy tests where the larger root radius causes a critical fracture event to occur much further away from the notch tip, the improved $\sigma_{F}$, due to reduction in segregation, etc, at higher an nealing temperatures leads to improved $C V N$ and $K_{A}$ values. The improvement in these properties is more pronounced in refined steel due to superior chemical homogeneity, lower sulphur levels and improved cleanliness.

Improvement in fracture toughness values with increasing annealing temperatures can be attributed to increased characteristic distance. The increase in characteristic distance appears to be associated with increase in grain
(1)

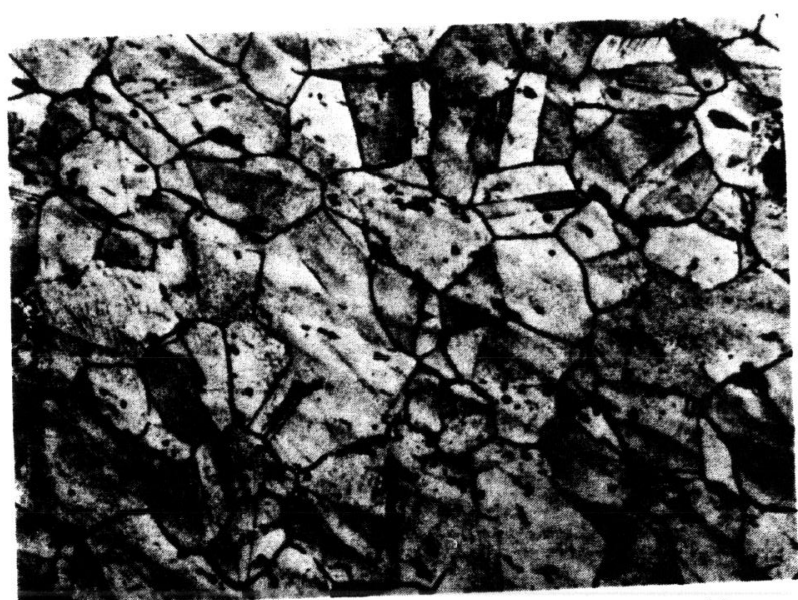

$\stackrel{44 \mu \mathrm{m}}{\longrightarrow}$

$(2$

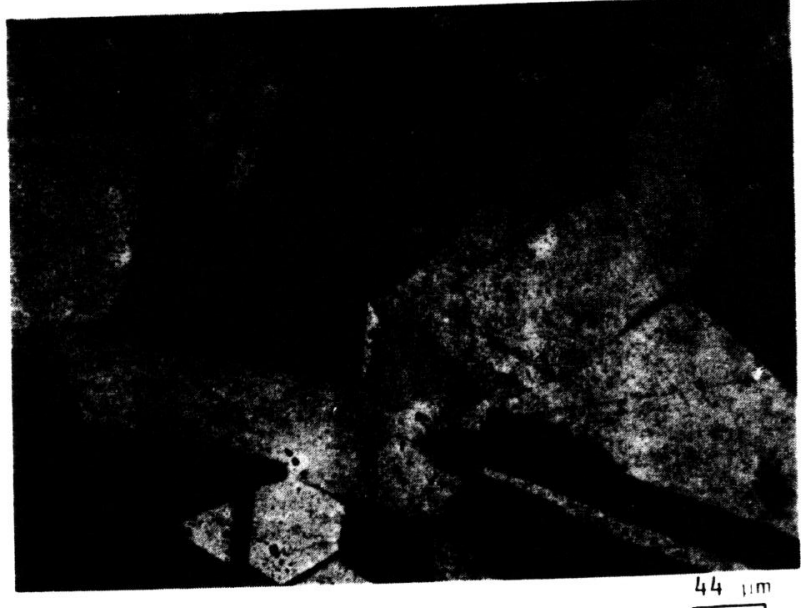

Fig 3b. Optical microstructures of AlsI 316 stainless steel (1) $1173 \mathrm{~K}$ annealed, (2) $1473 \mathrm{~K}$ annealed.

size (Fig. 3) as well as increase with higher temperature annealing.

Further, the toughness values have increased with increase in notch root Further, the toughness value radius at all annoack and the energy required to propagate a energy requi ired to nacture a fatigue precracked sample is 
(a)
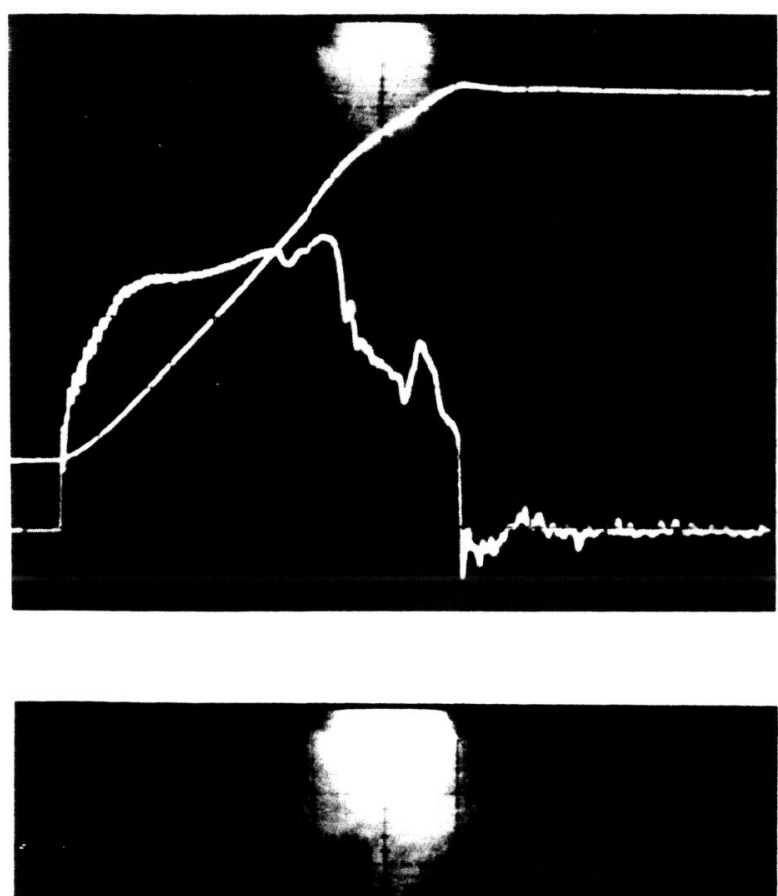

(b)

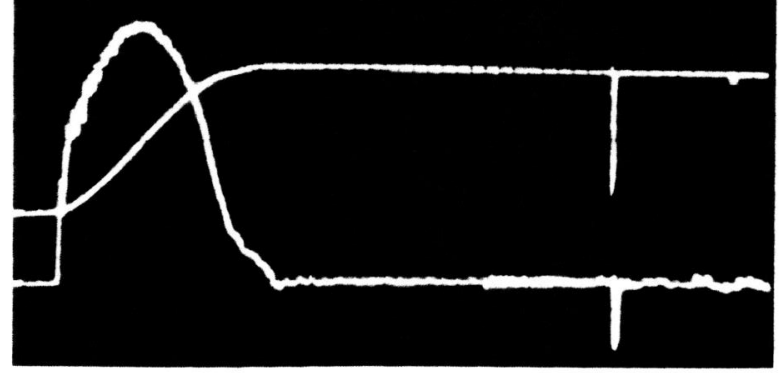

Fig. 4 Typical load (energy)/time curves for AlSI 316 stainless stee obtained on an instrumented impact tester (a) refined steel. (b) unrefined steel。

a measure of the propagation energy $\left(C_{p}\right)$, since virtually no energy will be required to nucleate the impact fracture (McDarmaid, 1980). A measure of nucleation energy can be obtained by subtracting the fatigue precracked impact strength $C_{p}$ from the measured charpy impact strength $C_{T}$ for any notch root radius and annealing temperature. A plot of $\left(C_{T}-C_{p}\right)$ against annealing temperature for two different notch root radii, for refined AISI 316

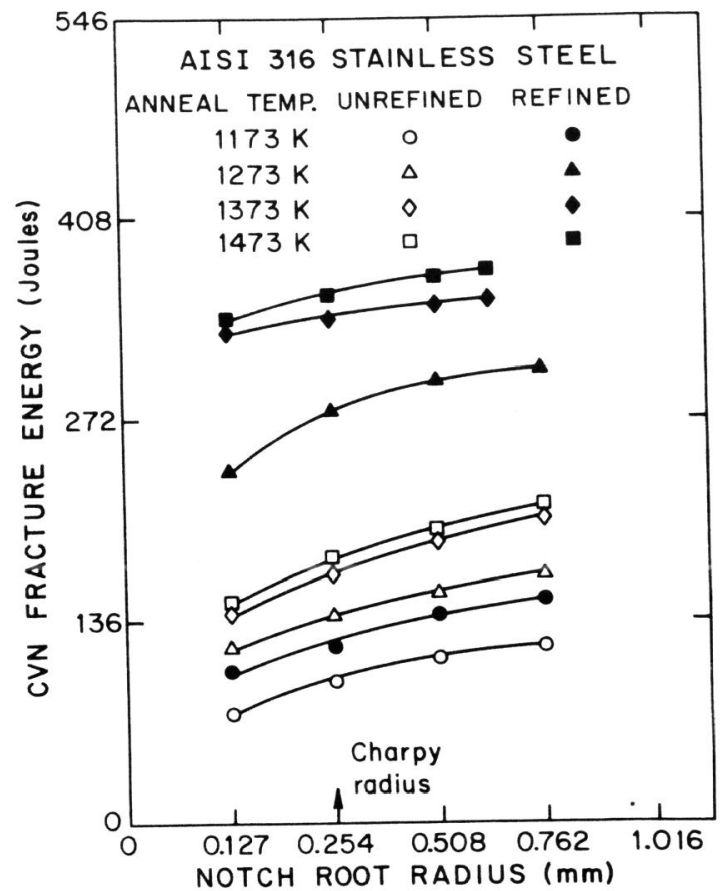

Fig 5 A plot of CVH fracture energy as a function of notch root radius $(0)$, in AISI 316 stainless steel.

stainless steel, is shown in Figure 10. It is clear from Fig. 10 that nucleation energy has increased with the increase in notch root radius and annealing temperature. Therefore, increases in both the nucleation and propagation energies have contributed to the increased toughness values.

\section{CONCLUSIONS}

(1) Refining of AISI 316 stainless steel was found to improve CVN and $K_{I C}$ values in comparison with the unrefined steel. This improvement in the values in conparison with the unrefined steel. and the reduction in sulphur content.

(2) Both the CVN fracture energy and apparent fracture toughness $K_{A}$ values of AISI 316 steel were improved with increase in annealing temperature. This was mainly attributed to increase in critical fracture stress $\sigma_{F}$ due to improved microstructural features such as reduction in segregation, etc。

(3) Plane strain fracture toughness values were improved with increase in annealing temperature. This was attributed to increased characteristic distance due to increased grain size and mean inclusion spacing. 


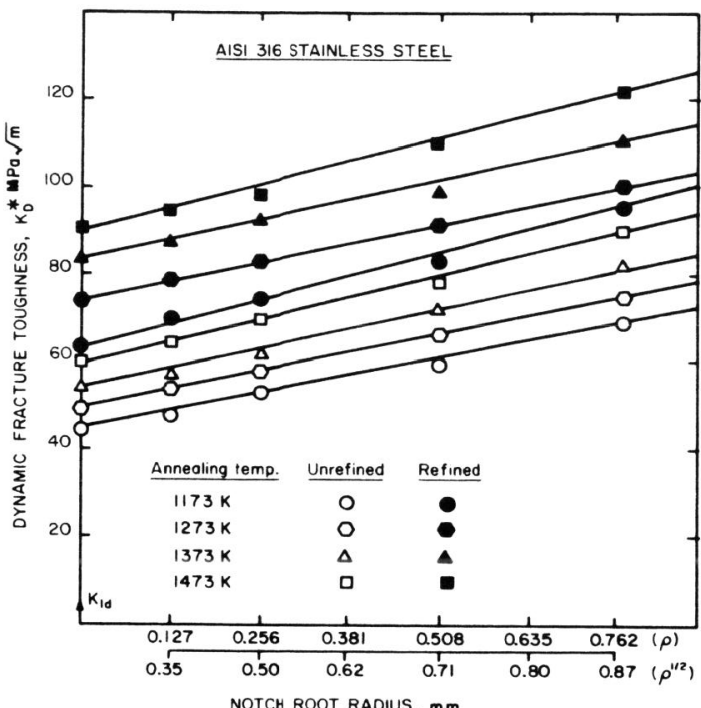

Fig。6. The relationship between toughness measured by the apparent dynamic fracture toughness ( $K_{A}$ ) from instrumental charpy tests and notch radius (o) in AISI 316 stainless steel.

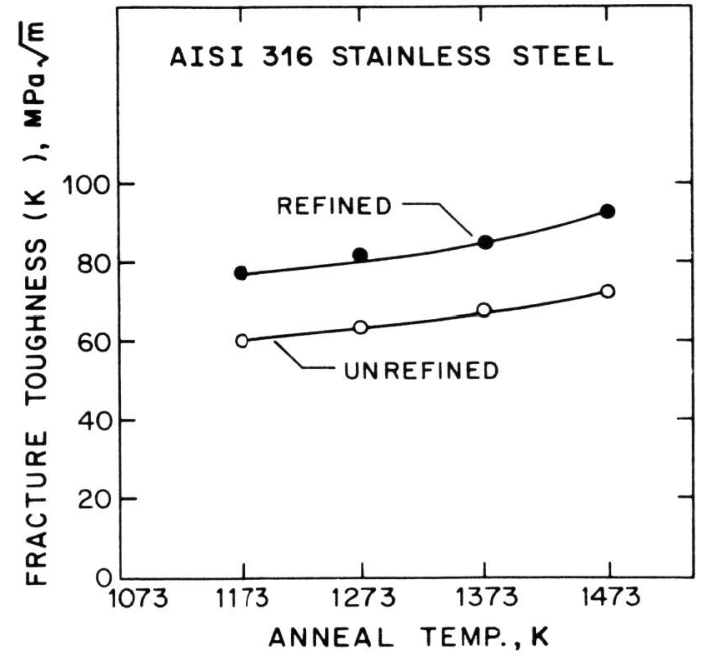

Fig. 7. A plot of fracture toughness as a function of annealing temperature.
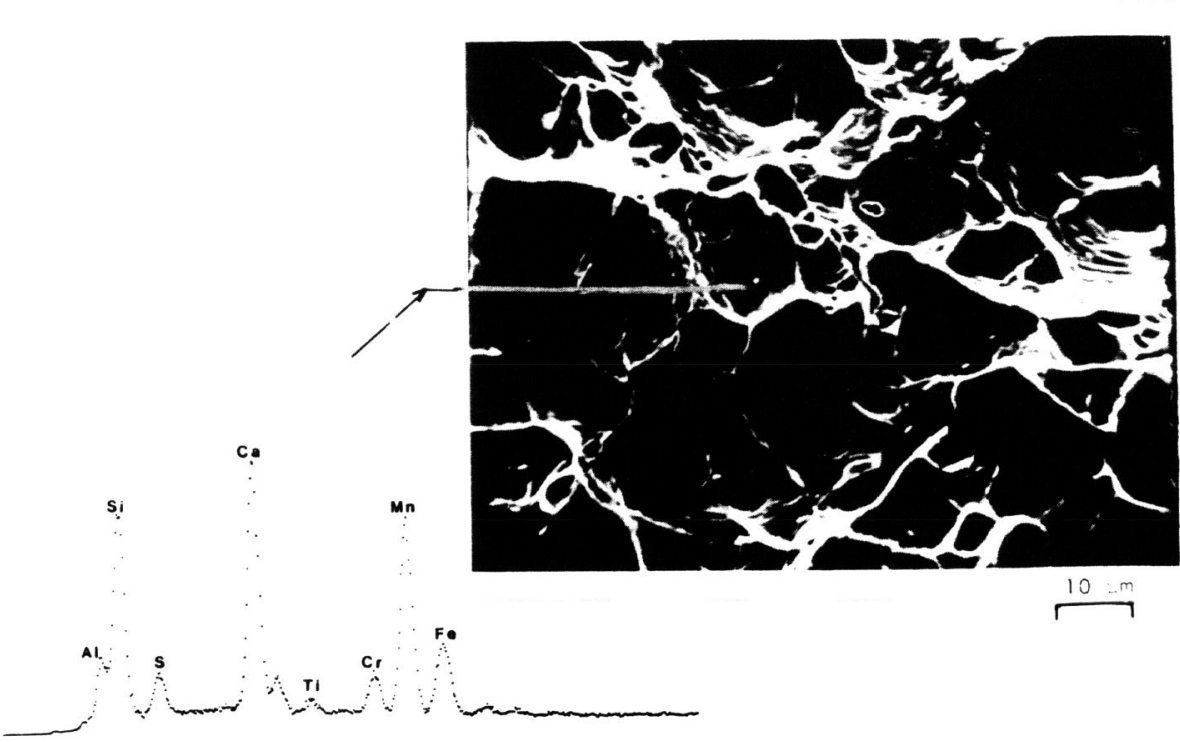

Fig. 3a SEM fractograph of refined AISI 316 stainless steel showing the dimple fracture caused by small sized globular MnS bearing inclusion.
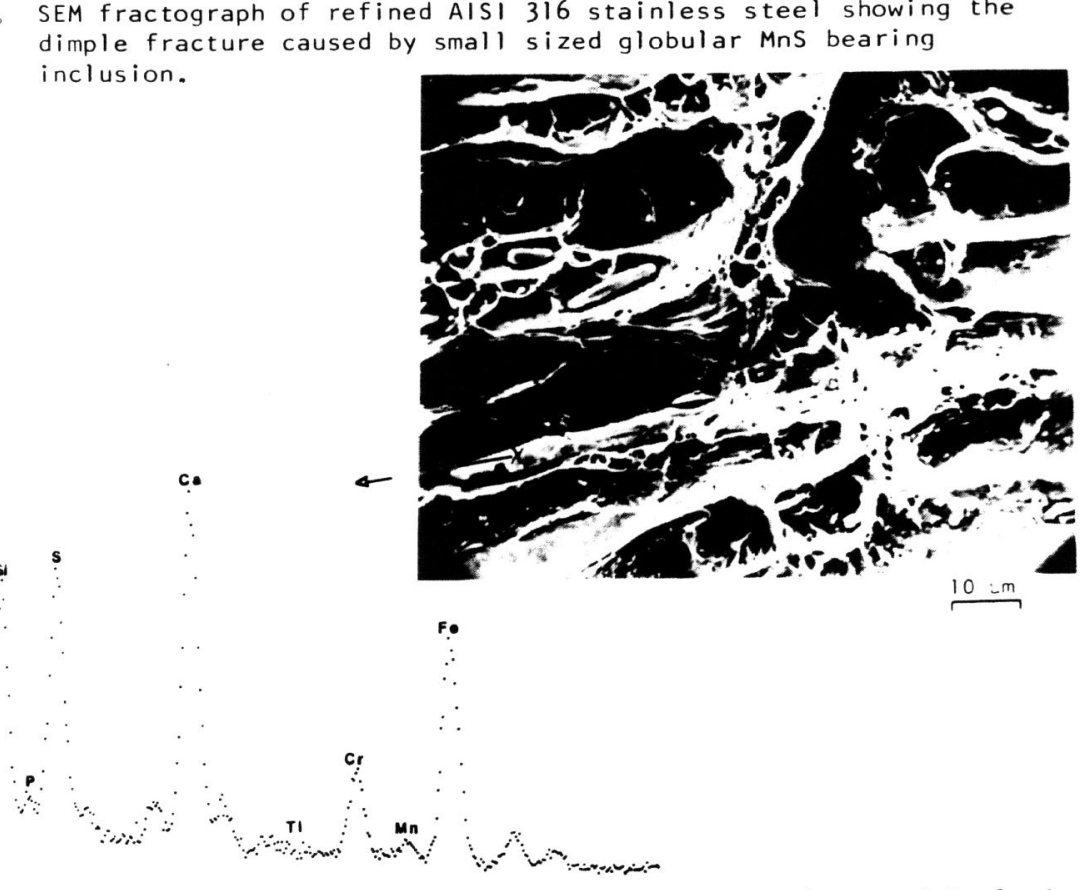

Fig. 8b SEM fractograph showing dimples caused by large elongated inclusions of complex composition in an unrefined AlsI 316 stainless steel. 
a

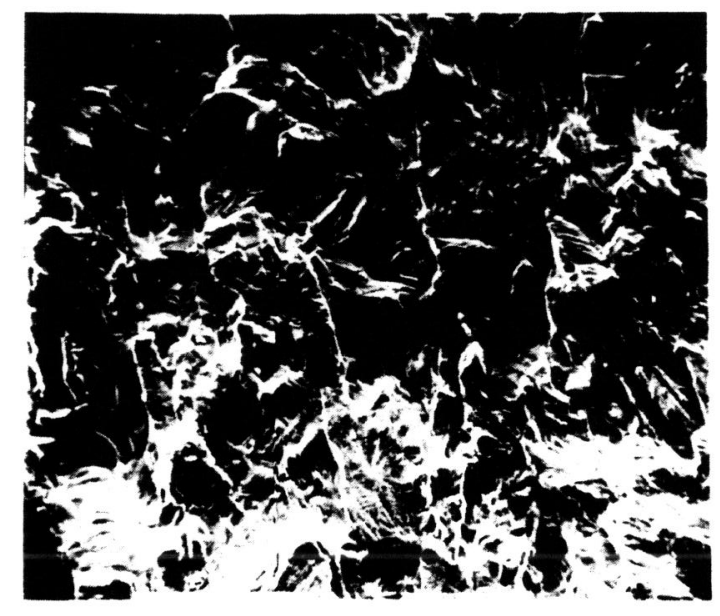

$50 \mu \mathrm{m}$

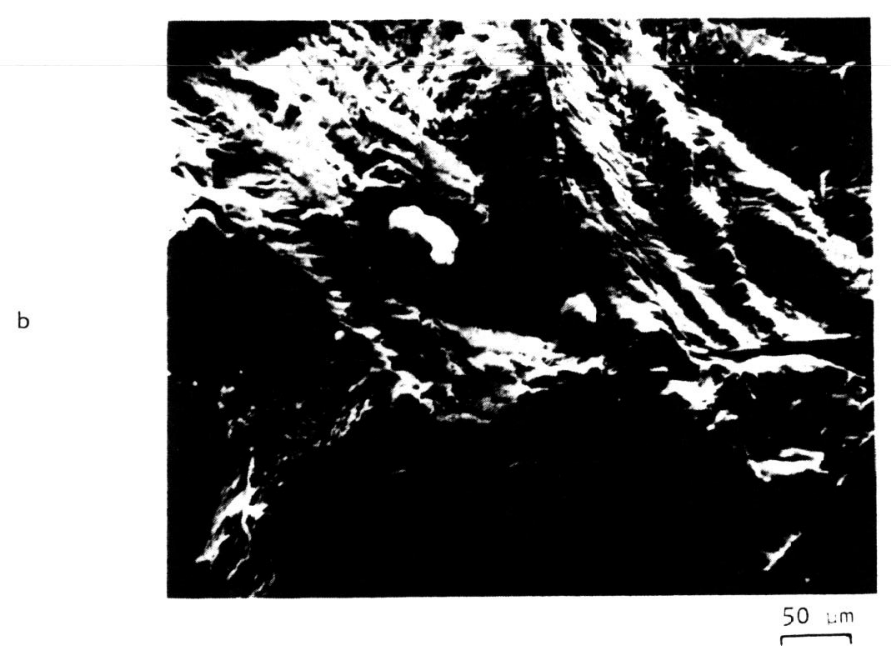

Fig. 9. SEM fractographs on charpy specimens of unrefined AISI 316 stainless steel: (a) $1173 \mathrm{~K}$ solution anneal, (b) $1473 \mathrm{~K}$ solution anneal.

(4) Toughness values were found to increase with increase in notch root radius. Both the initiation and propagation energy have contributed to this improvement.

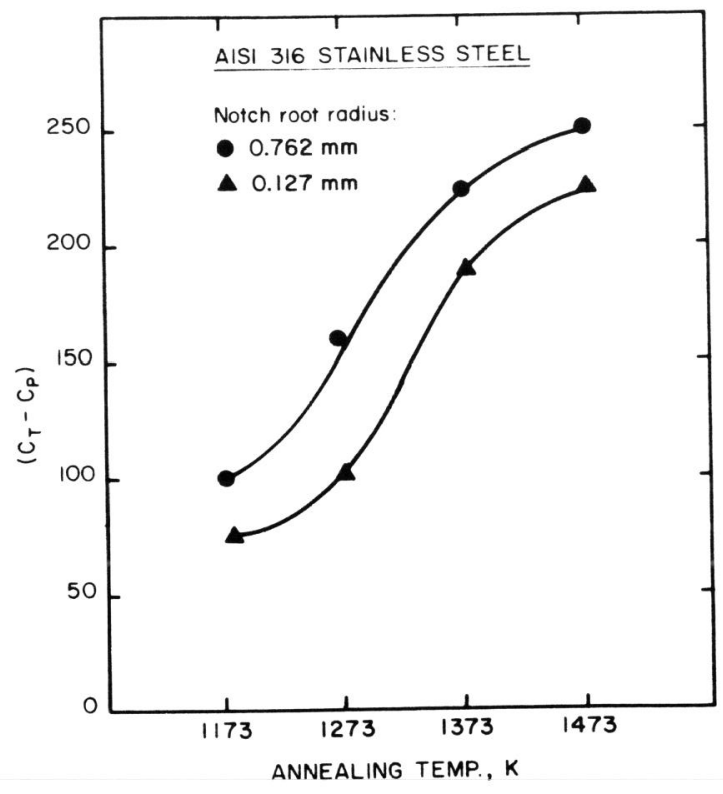

Fig. 10. Effect of annealing temperature and notch root radius on crack nucleation energy of refined AISI 316 stainless steel.

\section{REFERENCES}

Birkle, A. J., Klei, R. P. and Pellissier, G. E. (1966). Trans. ASM, 59, 981.

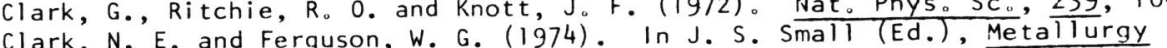
Clark, N. E. and eys p. 53. Y W. W. Clark, R. A., Zackay, V. F. and Parker, E. R. (1974). Metail. Trans., 5, 1663.

Metall. Trans., (1976). Royal Aircraft Establishment, Fairborough.

MCDishide,

McDarmaid, Detals Technol., $\frac{5}{7}, 7$.

Metall. Trans., 7A, 831 .

Ritchie, R. 0. and Horn, R. M. (1978). Metall. Trans., ISA, 331

Rogers, H. C. (1967). Ductility. ASM. P.31.

Schwal be, K. H. (1977). Eng. Fracture Mechanics, 9, 795. Dynatup Technical erver, W. L., Ireland, D. R. and Wullaert. R. Tha (a) als. Annual Book of ASTM Standards (1978), Part 10, Designation E399-74.

ASTM. Annual Book of AsTM standards (1978), Part 10, Designation E3gg-74. Zackay, V.F., Parker, E.

Phys. Sci., 236, 108. 
The authors gratefully acknowledge the help received from Mr. Tony Matuszewski of the Materials Division, Harnischfeger Corporation, Milwaukee, Wisconsin, in carrying out instrumented impact testing. Partial financial support from a Mineral Institute OSM Title III Fellowship for one of the authors (M.G. Hebsur) is also gratefully acknowledged. 